\title{
NATURAL AND MAN-MADE HEALTH HAZARDS IN RURAL SLOVAKIA
}

\author{
Gabriel Gulis ${ }^{1}$, Jana Kollarová2 ${ }^{2}$ Zuzana Dietzová ${ }^{2}$ Jana Labancová ${ }^{2}$, Martina Behanová ${ }^{3}$, Martina Ondrušová \\ ${ }^{1}$ Unit for Health Promotion Research, University of Southern Denmark, Esbjerg, Denmark \\ ${ }^{2}$ Regional Public Health Authority Košice, Košice, Slovak Republic \\ ${ }^{3}$ Pavel Jozef Šafárik University, Institute of Public Health Medical Faculty, Košice, Slovak Republic \\ ${ }^{4}$ National Cancer Registry of Slovak Republic, Bratislava, Slovak Republic
}

\section{SUMMARY}

Context: There is little information on health situation of the people of rural Slovak Republic. The rural environment is often a mixture of natural and man-made hazards, which under some conditions, might turn to be a health risk to humans.

Purpose: The aim of this study was to compare two regions of the Slovak Republic, two different hazards (natural and man-made), two different methods of health outcome measurement (routine statistics and individual diary based data).

Methods: Ecological study design with focus on cancer incidence analysis was employed in case of natural hazard analysis. Standardized incidence ratios (SIR) were calculated and are presented in paper. Observational study design was employed to study rural gardening practices and their impact on health.

Findings: Statistically significant differences in SIR were found in rural areas of Spis-Gemer Region (SGR) among males for lip, oral cavity and larynx (1.60, Cl 95\% 1.12-2.34), respiratory (1.25, Cl 95\% 1.01-1.55) and digestive organ cancers (1.22, Cl 95\% 1.01-1.47); hematopoetic cancers are significantly elevated among males in rural areas as well (1.58, $\mathrm{Cl} 95 \%$ 1.05-2.39). Pesticide use (83.1\% of gardeners use pesticides) without any protective equipment is still widespread among gardeners in rural Slovak Republic (16.9\%). The produced fruits and vegetables are substantial part of total fruit and vegetable consumption (51\% in summer and $42.7 \%$ in winter season) increasing the risk of exposure to pesticides.

Conclusion: Our study shows that on ecological level, mortality and morbidity statistics could be used to assess human health status in linkage to broad exposure measures (urban- rural); on dose response level (arsenic in soil) this method lacks sensitivity. Health survey and diary method on the other hand are useful tools in analysis of rural health especially with respect to man-made hazards.

Key words: rural health, cancer, gardening, pesticide

Address for correspondence: G. Gulis, Unit for Health Promotion Research, University of Southern Denmark, Niels Bohrsvej 9-10, 6700 Esbjerg, Denmark. E-mail: ggulis@health.sdu.dk

\section{INTRODUCTION}

There is a growing interest in rural health worldwide, however the definition of what rural is, is not fully clear. Muula (1) made an attempt to define rurality summing up different classification systems of rurality, mostly based on literature from the USA. Countries of the European Union define as rural areas those with pre-dominantly agricultural activities, where green zones with ecological functions prevail, low population density, inhabited zones spread across large areas, communities are of limited size, high physical work demanding employment possibilities are prevailing, there are natural beauties and a local or regional culture exists (2). In the Slovak Republic these communities are considered as rural, provided that they do not have a statute of a town; do have typical signs of housing; economic structure based on agriculture or forestry; less developed infrastructure and low population density. Most of them are below 5,000 inhabitants. Based on data of the statistical office of the Slovak Republic in 2005, there were a total of 2,891 municipalities among them 138 with a statute of a town. $55,4 \%$ of inhabitants $(2,986,802$ persons) lived in urban and $44,6 \%$ of inhabitants $(2,402,378$ persons) in rural settings (3). The average population density was about 110 inhabitants per $\mathrm{km}^{2}$. Using the OECD definition of rurality in 2002, about $63.3 \%$ of Slovak population lives in rural regions compared to about $37 \%$ of the total population of the European Union member states (4). The OECD definition is based on local administrative units and regions. Based on the definition (based on population density) of rurality by Eurostat (4), 85.3\% of Slovak population lives in scarcely populated areas compared to about $26.4 \%$ of the European Union member states population.

Rural environment is often a mixture of natural and man-made hazards, which under some conditions turns to be a health risk for humans. The presented study focused both on natural and man-made hazards in rural Slovak Republic with objective to put rural health on the agenda. The first part deals with natural heavy metal exposure in the region of Spiš-Gemer of Eastern part of Slovak Republic and analyzes health status of inhabitants with special focus on cancer incidence. The second part focuses on 
gardening practices and possible health consequences in a typical rural agricultural municipality of the southern part of the Slovak Republic.

With the support of the US EPA, a risk assessment study has been completed by the Regional Public Health Authority Institute in Košice in Spiš-Gemer region (SGR) (Table 1). The report concludes that lead, arsenic, mercury and in some cases chromium exposes especially children to higher risk due to their increased daily intake of these heavy metals. Epidemiological studies often describe heavy metal exposures mostly in occupational settings or related to one single exposure source such as drinking water. Studies describing truly environmental exposures for a large population over a long time are missing due to lack of similar populations. Ahsan and the HEALS group (5) conducted the "Health effects of arsenic longitudinal study" in Araihazar, Bangladesh on a population level, looking at different health outcomes such as premalignant and malignant skin tumors, total mortality, pregnancy outcomes, and children's cognitive development. Another population survey has been conducted by Rahman et al. (6), exposure assessment was based on drinking water intake in their study. Drinking water as main exposure route of arsenic has been frequently studied focusing on different cancers such as bladder, kidney, lung and skin (7-11). Pregnancy outcomes are also often linked to arsenic level in drinking water (12-19).

The second part of the study, in contrary to the first, assessed human exposures related to rural life. There are studies dealing with rural health issues, however, most of them addresses cancer experience of professional farmers, pesticide applicators or other well defined target groups (20-23). Exposure assessment under rural setting is rather complicated; interview based surveys or biomarkers present a possible solution. Our study aims to employ the cheaper interview survey method. Gardening practices of a cohort of traditionally rural and agricultural population was analyzed. Previous studies, such as the Trenčín gardening study by Hatiar, Hatiarová, Cook and Gulis described gardening practices in Trenčín (24), but failed to assess health status of gardeners. Our study, firstly collected data about self perceived health status and basic gardening practices and secondly selected participants were followed up by a health diary over one year period.

The main research question of the study was in fact to compare the role of natural and man-made exposures and assess the possibility of use of basic health data collection methods. The study did not aim to accept or reject a hypothesis (not possible with selected design) or prove dose-response relationships; the aim was rather to produce health data to justify a need for future, much deeper, more specific epidemiological studies on both subjects and help to put rural public health on agenda.

\section{METHODS}

The two sub-studies used different methods therefore they are presented as two subchapters. The research question (aim of the study), time, data and financial resources available were the most important factors in selection of methods.

\section{Natural Hazards Sub-study}

Ecological study design was employed in case of heavy metal study in Spiš-Gemer region (SGR). Two different analyses were conducted:

- The entire population of the region was analysed; demographic and health data from national statistic was used to conduct the analysis.

- The first analysis divided the settlements of the SG region into urban - rural status using Slovak national definition of rurality. Standardized morbidity ratios of cancers were calculated. Risk ratios were calculated by simply 2x2 table method comparing urban and rural municipalities within region of interest. Appropriate statistic such as $95 \%$ confidence intervals, P-values helped to assess the statistical strength of associations.

- The second analysis focused on dose-response relation (on ecologic, population based level) using cancer incidence as health outcome and arsenic concentration in soil as exposure indicator. Settlements were grouped into three contamination categories based on arsenic concentration in soil and standardized incidence ratios were calculated.

Morbidity (cancer incidence) analysis covered 1998-2002, whereas mortality data are for 2000-2004.

\section{Man-made Exposure Sub-study}

The gardener study employed an observational study design and lasted from September 2005 to April 2007 including analysis of data. In the first phase face-to-face interviews were conducted with a random sample of gardeners representing about $81 \%$ of total number of gardeners in selected town (sample size of 184 gardeners). The second phase turned this study into a small prospective observational study, where health data were collected via a diary. Pesticide use related data from a questionnaire survey allowed to create exposed and unexposed groups and conduct analysis producing relative risks with appropriate statistics (95\% confidence intervals, $\chi^{2}$ statistics, and P-values). However, due to relatively small sample size (40 diaries collected) we do present a rather qualitative analysis of these diaries. Access 2000, Excel 2000, R2.4.0 and Statcalc software's were employed to systematize and analyze the results of the study.

Table 1. Demographic characteristics of the SGR region by urban-rural status

\begin{tabular}{|l|c|c|c|c|c|c|c|c|}
\hline & Population & Mortality/1000 & $\begin{array}{c}\text { Suicide } \\
\text { rate/1000 }\end{array}$ & $\begin{array}{c}\text { Live } \\
\text { births/1000 }\end{array}$ & $\begin{array}{c}\text { Abortion } \\
\text { rate/1000 }\end{array}$ & $\begin{array}{c}\text { Low birth } \\
\text { weight/1000 }\end{array}$ & $\begin{array}{c}\text { \% of Roma } \\
\text { population }\end{array}$ & $\begin{array}{c}\text { As in soil } \\
\text { (mg/kg) }\end{array}$ \\
\hline Urban & 444381 & $\begin{array}{c}9.26 \\
(8.15-10.37)\end{array}$ & $\begin{array}{c}1.19 \\
(0.63-1.74)\end{array}$ & $\begin{array}{c}12.21 \\
(9.01-15.41)\end{array}$ & $\begin{array}{c}5.38 \\
(3.97-6.80)\end{array}$ & $\begin{array}{c}1.17 \\
(0.71-1.62)\end{array}$ & $\begin{array}{c}17.16 \\
(0.74-41.86)\end{array}$ & 61.36 \\
\hline Rural & 408657 & $\begin{array}{c}12.95 \\
(8.71-17.19)\end{array}$ & $\begin{array}{c}1.16 \\
(0.36-1.95)\end{array}$ & $\begin{array}{c}12.57 \\
(6.90-18.24)\end{array}$ & $\begin{array}{c}4.69 \\
(2.16-7.22)\end{array}$ & $\begin{array}{c}1.14 \\
(0.00-2.43)\end{array}$ & $\begin{array}{c}21.30 \\
(1.45-32.88)\end{array}$ & 71.04 \\
\hline
\end{tabular}




\section{RESULTS AND DISCUSSION}

\section{Natural Hazards Sub-study}

Table 1 presents the general demographic characteristics and arsenic in soil by urban-rural status of the SGR region (intervals in brackets signalize lower and upper interval within 1 standard deviation).

The mortality analysis focused on selected cancer mortalities using crude data (not age, gender specific data). Based on literature, we focused on cancer of larynx, trachea, bronchi and lung (C 32, 33 and 34), malignant melanoma (C 43) and bladder cancer (C67). Risk ratios by urban-rural status (rural as exposed) are presented in Table 2.

Table 3 presents cancer mortality of selected cancer by arsenic level in soil of residence place. None of the three selected cancer mortalities show statistically significant trend by changing arsenic concentration in soil of the municipality of residence.

Table 2. Urban-rural risk ratios of selected cancer mortality (rural as exposed)

\begin{tabular}{|l|c|c|c|}
\hline Cancer & RR & Cl 95\% & P-value \\
\hline $\begin{array}{l}\text { Malignant neoplasms } \\
\text { of larynx, trachea, } \\
\text { bronchus and lung }\end{array}$ & 1.31 & $1.05-1.63$ & 0.0121577 \\
\hline Malignant melanoma of skin & 0.46 & $0.20-1.05$ & 0.0572967 \\
\hline Malignant neoplasm of bladder & 0.64 & $0.29-1.40$ & 0.2582436 \\
\hline
\end{tabular}

Table 3. Cancer mortality of selected cancers by arsenic on soil level $(/ 100,000)$

\begin{tabular}{|l|c|c|c|}
\hline Cancer & $>50 \mathrm{mg} / \mathrm{kg}$ & $\begin{array}{c}30-50 \\
\mathrm{mg} / \mathrm{kg}\end{array}$ & $<30 \mathrm{mg} / \mathrm{kg}$ \\
\hline $\begin{array}{l}\text { Malignant neoplasms } \\
\text { of larynx, trachea, } \\
\text { bronchus and lung }\end{array}$ & 43.69 & 34.13 & 44.60 \\
\hline Malignant melanoma of skin & 4.16 & 2.99 & 3.72 \\
\hline Malignant neoplasm of bladder & 3.12 & 2.99 & 3.72 \\
\hline
\end{tabular}

Two different cancer incidence analyses were conducted. First, the villages of the SGR region were grouped by urban-rural status and second, arsenic concentration in soil served as exposure categorization variable. In both cases organ specific standardized cancer incidence ratios were calculated. Table 4 shows standardized incidence ratios (SIR) for urban rural categorization for both genders as well as males and females separately.

Statistically significant urban rural difference in cancer incidence was identified for all cancers, lip cancer, digestive organ cancers, respiratory cancer, skin cancer and leukemia's among males. Except skin cancer where there is a higher incidence in urban areas rural population is always at higher risk.
Table 5 presents the SIR's by levels of arsenic concentration measured in soil within villages and towns of SGR region.

The size of the population of the three exposure regions was $66,214,164,015$ and 187,091, respectively, from highest exposure to lowest. No statistically significant trends reflecting changing arsenic concentration in soil were identified. Urban-rural division seems to fit better for standardized cancer incidence analysis.

\section{Man-made Hazards Sub-study}

Participants were selected by random selection from the list of members of the Slovak gardener society - branch Zeliezovce; 184 gardeners (97 males and 81 females) participated in the survey and the overall response rate was $96.7 \%$.

The main characteristics of study participants are summarized in Table 6.

The study population was fairly stable as of residence place; mean duration of residence in municipality was 39.64 years (SD \pm 13.43 ); $60.7 \%$ of participants live in rented flat houses and $39.3 \%$ in own private house. The average number of people in one household was 3 (SD \pm 1.17 ).

Review of gardening practices is summarized in Table 7.

There were no differences in use of personnel protective equipments by gender.

The higher the education level, the lower pesticide use; university-level educated gardeners used significantly less pesticides compared with high school graduates or non matriculated gardeners.

Participants were asked to evaluate their health status as either they feel healthy or not healthy. In the beginning we had four categories to evaluate self reported health status, but due to the small sample size we merged them into two major ones. Out of the whole study population, $36 \%$ of females and $47.8 \%$ of males reported that they felt healthy compared to $9.6 \%$ of females and $6.7 \%$ of males who reported that they did not feel healthy. There was no significant difference by gender $\left(\chi^{2}=2.39\right.$; $\left.\mathrm{P}=0.12\right)$.

Information about prevalence of selected diseases in families of study participants was collected as well and is summarized in Table 8.

Study participants were also asked about the prevalence of depression; $10.7 \%$ of females and $2.8 \%$ of males reported depression. Females reported significantly higher prevalence of depression $\left(\chi^{2}=12.6 ; \mathrm{P}=0.0003\right)$

Sleeping disturbance was reported by $19.7 \%$ of females and $15.7 \%$ of males; females reported statistically higher prevalence of sleeping disturbance $\left(\chi^{2}=3.95 ; \mathrm{P}=0.046\right)$

$28.7 \%$ respondents were smokers, $24.7 \%$ were females and $32 \%$ were males. The mean number of daily smoked cigarettes was 12 (SD \pm 5 ) with no significant difference by gender. Smokers reported more often depression as non-smokers $\left(\chi^{2}=6.15\right.$; $\mathrm{P}=0.013$ )

In the beginning, 40 study participants agreed to participate in a prospective follow-up of health problems by diary method during 12 (9) months. Later, three participants dropped out and data was therefore collected from 37 study participants only; among them 22 females and 15 males. The most often stated health concerns are summarized in Table 9. 
Table 4. SIR for urban-rural division of SGR

\begin{tabular}{|c|c|c|c|c|c|c|c|c|c|c|}
\hline SIR & Male & & RR & $\mathrm{Cl} 95 \%$ & P-value & Female & & $\mathrm{RR}$ & $\mathrm{Cl} 95 \%$ & P-value \\
\hline 1998-2002 & Urban & Rural & & & & Urban & Rural & & & \\
\hline All cancers & 367.33 & 431.77 & 1.17 & $1.07-1.29$ & 0.00101 & 348.78 & 362.21 & 1.04 & $0.94-1.15$ & 0.45825 \\
\hline $\mathrm{C} 00-\mathrm{C} 14$ & 22.67 & 36.31 & 1.60 & $1.12-2.34$ & 0.01004 & 4.82 & 2.89 & 0.60 & $0.22-1.62$ & 0.30828 \\
\hline C15-C26 & 93.45 & 113.91 & 1.22 & $1.01-1.47$ & 0.04008 & 75.36 & 83.33 & 1.11 & $0.90-1.37$ & 0.35089 \\
\hline С30-С39 & 70.32 & 88.04 & 1.25 & $1.01-1.55$ & 0.04175 & 12.27 & 12.04 & 0.98 & $0.57-1.68$ & 0.94587 \\
\hline C40-C41 & 0.46 & 2.98 & 6.45 & $0.78-53.58$ & 0.04692 & 0.44 & 0.48 & 1.10 & $0.07-17.58$ & 0.94662 \\
\hline C43-C44 & 67.08 & 50.74 & 0.76 & $0.59-0.97$ & 0.03020 & 59.15 & 65.51 & 1.51 & $0.87-1.40$ & 0.40097 \\
\hline C45-C49 & 2.31 & 1.99 & 9.86 & $0.23-3.20$ & 0.8221 & 2.19 & 4.82 & 2.20 & $0.75-6.43$ & 0.14000 \\
\hline C50 & 0.93 & 0.50 & 0.54 & $0.05-5.93$ & 0.60659 & 67.04 & 60.21 & 0.90 & $0.71-1.14$ & 0.37261 \\
\hline C51-C63 & 39.32 & 48.75 & 1.24 & $0.92-1.67$ & 0.14658 & 62.66 & 55.87 & 1.11 & $0.70-1.14$ & 0.35892 \\
\hline C64-C68 & 24.98 & 34.82 & 1.39 & $0.98-1.99$ & 0.06559 & 17.09 & 15.89 & 0.89 & $0.59-1.48$ & 0.75947 \\
\hline C69-C72 & 9.72 & 5.97 & 0.61 & $0.30-1.25$ & 0.17401 & 3.51 & 5.30 & 0.93 & $0.61-3.76$ & 0.37059 \\
\hline C73-C75 & 3.24 & 1.99 & 0.61 & $0.18-2.10$ & 0.43252 & 7.01 & 6.26 & 0.89 & $0.43-1.86$ & 0.76207 \\
\hline C76-C80 & 8.79 & 10.45 & 1.19 & $0.64-2.21$ & 0.58585 & 6.13 & 8.67 & 1.41 & $0.70-2.84$ & 0.32923 \\
\hline C81-C96 & 17.58 & 27.85 & 1.58 & $1.05-2.39$ & 0.02717 & 16.21 & 19.75 & 1.22 & $0.78-1.90$ & 0.38351 \\
\hline D00-D09 & 2.78 & 2.98 & 1.08 & $0.35-3.33$ & 0.90006 & 7.89 & 9.15 & 1.16 & $0.61-2.21$ & 0.65088 \\
\hline D10-D36 & 2.31 & 1.99 & 0.86 & $0.23-3.20$ & 0.82213 & 3.07 & 3.85 & 1.26 & $0.46-3.46$ & 0.65861 \\
\hline D37-D48 & 1.39 & 2.49 & 1.79 & $0.43-7.5$ & 0.41788 & 3.94 & 8.19 & 2.08 & $0.93-4.66$ & 0.06998 \\
\hline
\end{tabular}

Table 5. SIR by arsenic concentration in soil of SGR region municipalities

\begin{tabular}{|c|c|c|c|c|c|c|}
\hline \multirow{2}{*}{ As in soil } & \multicolumn{3}{|c|}{ Males } & \multicolumn{3}{|c|}{ Females } \\
\hline & $>50 \mathrm{mg} / \mathrm{kg}$ & $30-50 \mathrm{mg} / \mathrm{kg}$ & $<30 \mathrm{mg} / \mathrm{kg}$ & $>50 \mathrm{mg} / \mathrm{kg}$ & $30-50 \mathrm{mg} / \mathrm{kg}$ & $<30 \mathrm{mg} / \mathrm{kg}$ \\
\hline $\mathrm{C} 00-\mathrm{C} 14$ & 26.73 & 26.83 & 42.31 & 4.56 & 2.35 & 5.85 \\
\hline C15-C26 & 114.95 & 89.04 & 105.76 & 85.58 & 64.70 & 96.57 \\
\hline C30-C39 & 89.29 & 64.65 & 84.61 & 13.17 & 10.00 & 14.63 \\
\hline C40-C41 & 1.60 & 1.22 & 3.02 & 0.00 & 1.18 & 0.00 \\
\hline C43-C44 & 53.46 & 71.35 & 45.33 & 70.39 & 49.99 & 68.77 \\
\hline C45-C49 & 3.21 & 1.83 & 0.00 & 2.53 & 5.29 & 1.46 \\
\hline C50 & 0.00 & 1.22 & 1.51 & 66.84 & 57.64 & 70.23 \\
\hline C51-C63 & 46.51 & 42.69 & 39.28 & 57.73 & 62.93 & 55.60 \\
\hline C64-C68 & 29.94 & 24.39 & 42.31 & 18.74 & 13.53 & 17.56 \\
\hline C69-C72 & 6.95 & 7.93 & 10.58 & 4.56 & 3.53 & 5.85 \\
\hline C73-C75 & 3.21 & 1.22 & 4.53 & 7.09 & 5.88 & 7.32 \\
\hline C76-C80 & 10.16 & 7.93 & 12.09 & 7.09 & 5.88 & 11.71 \\
\hline C81-C96 & 21.39 & 24.39 & 21.15 & 18.74 & 17.06 & 17.56 \\
\hline D00-D09 & 4.28 & 1.83 & 1.51 & 8.61 & 7.06 & 11.71 \\
\hline D10-D36 & 4.28 & 0.61 & 0.00 & 3.54 & 2.35 & 5.85 \\
\hline D37-D48 & 2.14 & 0.61 & 4.53 & 5.06 & 5.88 & 8.78 \\
\hline
\end{tabular}


Table 6. Characteristics of study participants

\begin{tabular}{|l|l|c|c|}
\hline \multirow{5}{*}{ Age } & & Male & Female \\
\hline & Minimum age & 30 & 38 \\
\cline { 2 - 4 } & Maximum age & 75 & 83 \\
\cline { 2 - 4 } & Mean age & $51.25 \pm 10.26$ & $51.95 \pm 7.95$ \\
\hline \multirow{5}{*}{ Education } & Basic & $14(14.4 \%)$ & $11(13.5 \%)$ \\
\cline { 2 - 4 } & High school without graduation & $39(40.2 \%)$ & $13(16 \%)$ \\
\cline { 2 - 4 } & High school with graduation & $38(39.2 \%)$ & $51(63 \%)$ \\
\cline { 2 - 4 } & University & $6(6.2 \%)$ & $6(7.5 \%)$ \\
\hline \multirow{2}{*}{ Employment status } & Short term unemployed & $2(2 \%)$ & $3(3.7 \%)$ \\
\hline & Long term unemployed & $19(19.6 \%)$ & $8(9.8 \%)$ \\
\hline & Employed & $55(56.7 \%)$ & $53(65.5 \%)$ \\
\hline
\end{tabular}

Table 7. Review of gardening practices

\begin{tabular}{|c|c|}
\hline Time spent in garden as percentage of leisure time & $43 \pm 26 \%$ \\
\hline Mean number of years being a gardener & $23 \pm 10$ \\
\hline Production of own garden products as main motivation of gardening & $66 \%$ \\
\hline Relaxation, hobby as main motivation of gardening & $34 \%$ \\
\hline Share of own production on total fruit and vegetable consumption - summer & $51 \pm 26.6 \%$ \\
\hline Share of own production on total fruit and vegetable consumption - winter & $42.7 \pm 24 \%$ \\
\hline Use of fertilizers & $90.4 \%(85.4-94.6)$ \\
\hline Use of fertilizers once in 3 years & $37.1 \%$ \\
\hline Use of fertilizers once a year & $48.3 \%$ \\
\hline Use of fertilizers more than once a year & $5.1 \%$ \\
\hline No use of fertilizers & $9.6 \%$ \\
\hline Use of natural fertilizers only & $50.3 \%$ \\
\hline Use of combined natural and artificial fertilizers & $24.2 \%$ \\
\hline Use of artificial fertilizers only (nitrogen based) & $25.5 \%$ \\
\hline Pesticide use in total & $83.1 \%(77.3-88.9)$ \\
\hline Pesticide use $1 x$ a year & $6.1 \%$ \\
\hline Pesticide use $2 x$ a year & $23.6 \%$ \\
\hline Pesticide use $3 x$ a year & $22.3 \%$ \\
\hline Pesticide use $4 x$ a year & $20.3 \%$ \\
\hline Pesticide use $5 x$ a year & $16.9 \%$ \\
\hline Pesticide use $6 \mathrm{x}$ a year & $7.4 \%$ \\
\hline Pesticide use $7 x$ a year & $2.0 \%$ \\
\hline Pesticide use more than $10 x$ a year & $1.4 \%$ \\
\hline \multicolumn{2}{|l|}{ Use of personnel protective equipments while spraying pesticides: } \\
\hline None & $16.9 \%$ \\
\hline Gloves & $70.9 \%$ \\
\hline Clothes and protective face mask & $32.4 \%$ \\
\hline
\end{tabular}


Table 8. Prevalence of selected disease in families of study participants

\begin{tabular}{|l|c|c|}
\hline & N & $\%$ \\
\hline Cardiovascular diseases & 147 & 82.6 (Cl 95\% 76.7-88.5) \\
\hline Neoplasms & 53 & 29.8 (Cl 95\% 22.8-36.8) \\
\hline Diabetes mellitus & 71 & 39.9 (Cl 95\% 32.4-47.4) \\
\hline Allergies & 59 & 33.1 (Cl 95\% 25.9-40.2) \\
\hline Chronic respiratory diseases & 19 & 10.7 (Cl 95\% 5.9-15.5) \\
\hline
\end{tabular}

Table 9. Absolute numbers and percentage of occurrence of health problems among study participants in follow-up study

\begin{tabular}{|l|c|c|}
\hline & N & $\%$ \\
\hline Neurological problems, headache, migraines & 24 & 64.9 \\
\hline Musculoskeletal problems & 21 & 56.8 \\
\hline Digestive track problems & 17 & 45.9 \\
\hline Respiratory problems & 14 & 37.8 \\
\hline Cardiovascular disease & 13 & 35.1 \\
\hline Gynecological problems & 9 & $40.9+$ \\
\hline Skin problems & 9 & 24.3 \\
\hline Toothache & 6 & 16.2 \\
\hline Allergies & 5 & 13.5 \\
\hline Injuries, accidents & 5 & 13.5 \\
\hline Endocrine problems & 4 & 10.8 \\
\hline Mental health problems & 2 & 5.4 \\
\hline
\end{tabular}

+ calculated for females only

\section{DISCUSSION}

\section{Natural Hazard Sub-study}

As of the size, the urban and rural population is quite comparable, however, urban consists of 8 municipalities and rural of 90 municipalities. All cause mortality was significantly higher in rural as well as in urban areas; risk ratio is 1.24 (CI 95\% 1.19-1.29). Unfortunately, due to lack of residential place specific mortality data by age, gender and a detailed standardized mortality ratio analysis was not possible to conduct. Traditionally strong social cohesion might be one of the causes of slightly lower suicide and abortion rates (not statistically significant) among rural population. There is no significant difference as of live births and low birth weight prevalence between urban and rural population. In the Slovak Republic, the Roma population is one of the largest minorities and is often considered a very vulnerable population as of the health status. Therefore we include the share of Roma population on total urban and rural population; the mean is higher in rural areas, but the standard deviation in urban areas is broader, so it is unlikely to expect a significant difference which would explain major health differences. Arsenic concentration in soil is higher in rural areas. Unfortunately, due to the lack of data on the municipality level we cannot get statistics on other socio-economic determinants such as education, income, employment by urban-rural status.
There are a couple of points to mention with regard to demographic, mortality and morbidity analyses.

First, incomplete data collection system disables detailed and age standardized analysis of mortality; data is missing on most of socio-economic variables, population data lacks precise ethnicity data. All this makes the analysis rather hypothetical. There is a clear and statistically significant higher crude death rate in rural compared to urban population. This increased mortality is unlikely to be explained by the percentage of the Roma population. Social ties seem to be stronger in rural population resulting in slightly lower abortion and low birth weight prevalence.

Statistically significantly increased risk in rural areas was measured for mortality of cancer of larynx, tracheas, bronchi and lung; this association was confirmed for males only by cancer incidence analysis as well. Furthermore, there is an increased cancer incidence among rural males for tumors of lip, oral cavity and pharynx, respiratory tumors, digestive organ tumors and malignant neoplasm's stated or presumed to be primary of lymphoid, haematopoietic and related tissue. Rural life seems to be protective in case of malignant melanoma (mortality level) and the whole skin cancer group (incidence level). There was no statistically significant trend identified due to changing arsenic concentration levels in municipalities neither in mortality nor in incidence.

In comparison of our findings with literature survey data summarized in Table 2, we may identify a certain level of congruity. Significantly higher respiratory cancer prevalence was identified in rural areas, where arsenic in soil is higher as well. The question is why this association is not visible in direct arsenic concentration in soil and cancer incidence (mortality)? The answer, very likely, has to do a lot with our study design. Ecologic study design cannot identify individual exposures both as of the main exposure and potential confounders and/or effect modifiers. "Ecologic fallacy" is usually enlisted as the most important bias of population based ecologic studies and our study is not a difference. An individual level, case control or cohort study would be much more powerful to analyze such associations.

\section{Man-made Hazards Sub-study}

Despite the fact that urban-rural differences are widely recognized in public health literature most of the studies deal with only one key determinants of health related to this inequality, the role of access to health care $(25,26)$.

An important problem related to rural health and pesticide use related studies is exposure assessment. In occupational health studies there are possibilities to collect biomonitoring samples and/or reconstruct major application events $(27,28)$; this is not possible in general populations who use pesticides for their gardening hobby. Data from the Slovak veterinary and agriculture inspection warns that substantial amount of own production might be contaminated by pesticides or their residues and contribute to general body burden by chemicals in rural population. Another, direct route of exposure is due to lack of use of protective equipments while spraying pesticides in their own garden. Similar data were found in Slovakia in Trenčín area by gardener study in the end of 90-ties (24). Although pesticide use declined during last decades in Slovakia, spraying of gardens is still a widely used practice as our study participants stated. 
Our cross-sectional study complemented by a short and small size pilot follow-up can not make solid conclusions. However, taking in account both high prevalence of different diseases in families of study participants and frequencies of health problems reported during follow-up allow us to express our agreement with Salameh and his theory of effect of pesticide use in rural areas on the overall health status of all citizens living in area (29). Our sample, representing $81 \%$ of all gardeners in municipality would be considered as representative not only for the municipality, but also for the whole region. However, the sample is not representative for the whole Slovak Republic, as gardening in different regions is linked to environmental conditions and therefore use of pesticide varies by products grown in gardens.

The relatively high percentage of study participants who feel healthy could be explained by improving socio-economic conditions (30) but also by own health perception. In rural areas understanding of health is often equal to absence of disease (31). The finding around prevalence of disease in families of our study participants corresponds very well with published literature (32, $33,34)$. The high occurrence of neoplasms, $29.8 \%$ is especially alarming and calls for detailed study and intervention. As Arcury (35) stated long-term exposure to pesticide could result in increased incidence of neoplasm, neurological problems and reproductive disorders. These categories of health problems are all present in our small sample both in survey and short followup part.

Another novelty of our study is focused on mental health disorders. Both in case of depression and sleep disturbances we found significant difference by gender; this finding could be well compared with that of Averina (36). Mental health problems are significantly higher among females as males in our study and smokers suffer more often from depression as non-smokers.

The diary method for health problem data collection is not new in general (37) however; to our knowledge this is the first study where we attempted to use this method to collect information about health of a rural population in a transition country. Local media played a positive role by publishing a preliminary report on the study and asking for participation. In general, about 25\% of the total study participants agreed to participate also in followup and only 3 out of 40 dropped out in what could be considered a success. The diary consisted of two parts; the first asked for data based on visit at the medical doctor, the second aimed to collect data about health events which did not result in visit of a doctor. Interestingly enough, the second table remained close to empty, showing that people in rural areas are used to visit the doctor immediately after a health concerns present itself. This conclusion is extremely significant if we take in account that access to health care in rural areas is clearly worsening (a hospital in study municipality was closed right after the study concluded) and the population is aging. Females did the reporting in diary in more detailed way compared with males. This is in good compliance with general knowledge that females are more health conscious than males.

\section{General Discussion}

Lack of health data including mortality statistics on local, municipality level is a key factor when planning and conducting ecologic analysis in Slovak Republic. Due to lack of mortality data we were unable to complete a detailed mortality analysis in selected SGR study region. On the other hand, cancer incidence data kindly provided by National Cancer Registry allowed for standardized incidence ratio analysis under two exposure scenarios. The simplest, but much broader categories of urban vs. rural exposure categories gave clearar results as specific arsenic in soil concentration based exposure scenario. The study design, use of observational studies exposes our findings to the most important criticism and uncertainties. Observational studies, whether ecologic or cross-sectional cannot test and prove hypothesis; their objective is to generate hypothesis for future research. An individual study subject based, cohort or case-control study could only provide the answer whether a summary of all rural exposures (physical environment, gardening practices, social hazards, health care access, etc...), or a single exposure coming from natural environment is the most important one. To answer this question would be extremely important for public health policy making and policy prioritization. Exposure assessment is another uncertainty in both presented sub-studies. Due to design limitations given by available resources it was not possible to include all possible confounders and/or effect modifiers into study. There are published studies which employed analytical design on arsenic (and other heavy metals) and cancer is usually on higher level of epidemiological evidence; some of them we refer to but most of them we do not due to our aim to open a discussion on complexity of different exposures in rural areas. Unfortunately, several times during the study we were faced with situations where more could be done even with the available study design, but data do not exist, or access to data was not possible. This is an important finding and shows that even observational study design can contribute to policy making by identification of gaps, for example in data collection.

As to the main research question of our study we can certainly conclude that both natural and man-made hazards are important regarding their impact on health of rural population in Slovak Republic. Ecologic study design used in this study could confirm this fact, but not analyze it in depth.

\section{CONCLUSIONS}

The main objective of our study was to analyze rural health risks in two different areas of Slovak Republic, evaluate data availability and discuss options of different exposure classification choices.

In Eastern Slovakian „Spiš-Gemer Region“ elevated cancer risk was identified for all cancers, lip, digestive organs, respiratory cancer and leukemia's for males living in rural areas. The arsenic exposure level analysis did not provide statistically significant trend in cancer incidence. This signalizes, that a mixture of different hazards group under „rural“ exposure term might be more suitable to identify health effects and plan potential interventions.

The gardener study describes gardening practices in a relatively large and stable gardening population in Southern Slovakia. Pesticide use is still a significant hazard which compared with relatively large use of own garden products in diet might create an important exposure scenario. Use of health diaries to collect health outcome information of gardeners prospectively proved to 
be a valid option to collect more information on health of rural population.

In summary of both parts of our study we might conclude that only a well designed analytical study (case-control or cohort) which would collect individual data on natural and work place exposures, social hazards, health care access and use as well as health behavior and real time spent under different exposures could clarify main health issues linked to rural life.

\section{Acknowledgment}

The authors acknowledge the support by grant from Iowa-Fogarty International Training and Research in Environmental and Occupational Health of the University of Iowa which made this project possible.

\section{REFERENCES}

1. Muula AS. How do we define 'rurality' in the teaching on medical demography? Rural Remote Health. 2007 Jan-Mar;7(1):653.

2. Tvrdonova J. Conceptual framework of renewal of rural Slovakia and develoment of villages in Slovakia. In: Natural treasures and cultural heritage of Gemer region. Nitra: SPU; 1999. (In Slovak.)

3. Eurostat. Demographic outlook: national reports on the demographic developments in 2005 [monograph on the Internet]. Luxembourg: Office for Official Publications of the European Communities; 2007 [cited 2009 Sep 14]. Available from: http://epp.eurostat.ec.europa.eu/cache/ ITY_OFFPUB/KS-RA-07-001/EN/KS-RA-07-001-EN.PDF.

4. Eurostat. Agricultural statistics: data 1995-2004 [monograph on the Internet]. Luxembourg: Office for Official Publications of the European Communities; 2006 [cited 2009 Sep 14]. Available from: <http://epp. eurostat.ec.europa.eu/cache/ITY_OFFPUB/KS-ED-06-001/EN/KS-ED06-001-EN-TOC.PDF>

5. Ahsan H, Chen Y, Parvez F, Argos M, Hussain AI, Momotaj H, et al. Health Effects of Arsenic Longitudinal Study (HEALS): description of a multidisciplinary epidemiologic investigation. J Expo Sci Environ Epidemiol. 2006 Mar;16(2):191-205.

6. Rahman M, Vahter M, Wahed MA, Sohel N, Yunus M, Streatfield PK, et al. Prevalence of arsenic exposure and skin lesions. A population based survey in Matlab, Bangladesh. J Epidemiol Community Health. 2006 Mar;60(3):242-8.

7. Chen CJ, Chen CW, Wu MM, Kuo TL. Cancer potential in liver, lung, bladder and kidney due to ingested inorganic arsenic in drinking water. Br J Cancer. 1992 Nov;66(5):888-92.

8. Tsuda T, Babazono A, Yamamoto E, Kurumatani N, Mino Y, Ogawa T, et al. Ingested arsenic and internal cancer: a historical cohort study followed for 33 years. Am J Epidemiol. 1995 Feb 1;141(3):198-209.

9. Hopenhayn-Rich C, Biggs ML, Smith AH. Lung and kidney cancer mortality associated with arsenic in drinking water in Córdoba, Argentina. Int J Epidemiol. 1998 Aug;27(4):561-9.

10. Smith AH, Goycolea M, Haque R, Biggs ML. Marked increase in bladder and lung cancer mortality in a region of Northern Chile due to arsenic in drinking water. Am J Epidemiol. 1998 Apr 1;147(7):660-9.

11. Haque R, Mazumder DN, Samanta S, Ghosh N, Kalman D, Smith MM, et al. Arsenic in drinking water and skin lesions: dose-response data from West Bengal, India. Epidemiology. 2003 Mar;14(2):174-82.

12. Von Ehrenstein OS, Guha Mazumder DN, Hira-Smith M, Ghosh N, Yuan Y, Windham G, et al. Pregnancy outcomes, infant mortality and arsenic in drinking water in West Bengal, India. Am J Epidemiol. 2006 Apr 1;163(7):662-9.

13. Ahmad SA, Sayed MH, Barua S, Khan MH, Faruquee MH, Jalil A, et al. Arsenic in drinking water and pregnancy outcomes. Environ Health Perspect. 2001 Jun;109(6):629-31.

14. Hopenhayn-Rich C, Browning SR, Hertz-Picciotto I, Ferreccio C, Peralta $\mathrm{C}$, Gibb H. Chronic arsenic exposure and risk of infant mortality in two areas of Chile. Environ Health Perspect. 2000 Jul;108(7):667-73.

15. Börzsönyi M, Bereczky A, Rudnai P, Csanady M, Horvath A. Epidemiological studies on human subjects exposed to arsenic in drinking water in southeast Hungary. Arch Toxicol. 1992;66(1):77-8.

16. Yang CY, Chang CC, Tsai SS, Chuang HY, Ho CK, Wu TN. Arsenic in drinking water and adverse pregnancy outcome in an arsenic-endemic area in northeastern Taiwan. Environ Res. 2003 Jan;91(1):29-34.
17. Aschengrau A, Zierler S, Cohen A. Quality of community drinking water and the occurrence of spontaneous abortion. Arch Environ Health. 1989 Sep-Oct;44(5):283-90.

18. Ihrig MM, Shalat SL, Baynes C. A hospital-based case-control study of stillbirths and environmental exposure to arsenic using an atmospheric dispersion model linked to a geographical information system. Epidemiology. 1998 May;9(3):290-4.

19. Hopenhayn C, Ferreccio C, Browning SR, Huang B, Peralta C, Gibb H, et al. Arsenic exposure from drinking water and birth weight. Epidemiology. 2003 Sep;14(5):593-602.

20. Meyer TE, Coker AL, Sanderson M, Symanski E. A case-control study of farming and prostate cancer in African-American and Caucasian men. Occup Environ Med. 2007 Mar;64(3):155-60.

21. Hoppin JA, Umbach DM, London SJ, Lynch CF, Alavanja MC, Sandler DP. Pesticides associated with wheeze among commercial pesticide applicators in the Agricultural Health Study. Am J Epidemiol. 2006 Jun 15;163(12):1129-37.

22. Provost D, Cantagrel A, Lebailly P, Jaffré A, Loyant V, Loiseau H, et al. Brain tumours and exposure to pesticides: a case-control study in southwestern France. Occup Environ Med. 2007 Aug;64(8):509-14.

23. Bencko V, Slamova A. Best practices for promoting farmers' health: the case of arsenic history. J Public Health. 2007 Aug;15(4):279-88.

24. Hatiar K, Hatiarova K, Cook MT, Gulis G. Trencin gardener study 2003 [unpublished results].

25. Ruysbroek A, Droomers M, Westert GP. Urban-rural differences in GP care utilization: the effect of social support attitude on visiting the general practioner. 12th EUPHA conference: Urbanisation and Health: New Challenges in Health Promotion and Prevention. Eur J Public Health. 2004;14 Suppl 1;6.

26. Klumbiene J, Petkeviciene J. Self-rated health and primary health care accessibility: urban-rural differences. 12th EUPHA conference: Urbanisation and Health: New Challenges in Health Promotion and Prevention. Eur J Public Health. 2004;14 Suppl 1:63-4.

27. Hepworth SJ, Bolton A, Parslow RC, van Tongeren M, Muir KR, McKinney PA. Assigning exposure to pesticides and solvents from self-reports collected by a computer assisted personal interview and expert assesment of job codes: the UK Adult Brain Tumour Study. Occup Environ Med. 2006 Apr;63(4):267-72.

28. Chen Z, Stewart PA, Davies S, Giller R, Krailo M, Davis M, et al. Parental occupational exposure to pesticides and childhood germ-cell tumors. Am J Epidemiol. 2005 Nov 1;162(9):858-67.

29. Salameh P, Waked M, Baldi I, Brochard P, Saleh BA. Respiratory diseases and pesticide exposure: a case-control study in Lebanon. J Epidemiol Community Health. 2006 Mar;60(3):256-61.

30. OECD Economic surveys: Slovak Republic 2007. Paris: OEDC Publishing; 2007.

31. Humphreys J, Rolley F. Health and health care in rural Australia: a literature review. Armidale: University of New England; 1991.

32. American Public Health Association [homepage on the Internet]. National Public Health Week, Fact Sheets. Eliminating health disparities: communities moving from statistics to solutions. Toolkit [updated 2004 Apr 5-11; cited 2009 Sep 14]. Available from: http://www.apha.org/NR/rdonlyres/ DF497A70-8747-427A-BD93-B943FC9B6985/0/RuralPHW04_Facts. pdf.

33. Healthy people [homepage on the Internet]. Healthy People 2010 [cited 2009 Sep 14]. Available from: http://www.healthypeople.gov/.

34. Kalediene R, Petrauskiene J. Regional life expectancy patterns in Lithuania. Eur J Public Health. 2000 Jun;10(2):101-4.

35. Arcury TA, Quandt SA, Austin CK, Preisser J, Cabrera LF. Implementation of EPA's Worker Protection Standard training for agricultural laborers: an evaluation using North Carolina data. Public Health Rep.1999 Sep-Oct;114(5):459-68.

36. Averina M, Nilssen O, Brenn T, Brox J, Arkhipovsky VL, Kalinin AG. Social and lifestyle determinants of depression, anxiety, sleeping disorders and self-evaluated quality of life in Russia - a population-based study in Arkhangelsk. Soc Psychiatry Psychiatr Epidemiol. 2005Jul;40(7):511-8.

37. American Statistical Association [homepage on the Internet]. Verbrugge LM. Health diaries. 1978 [cited 2009 Sep 14]. Available from: http://www. amstat.org/Sections/Srms/Proceedings/papers/1978_054.pdf .

Received February 26, 2009 Accepted in revised form May 11, 2009 